\title{
Pengaruh Variasi Perendaman Beton Purun Tikus Terhadap Kuat Tekan dan Kuat Lentur Beton
}

\author{
Ani Firda Firda ${ }^{1}$; Indra Syahrul Fuad ${ }^{2}$ \\ ${ }^{1,2}$ Jurusan Teknik Sipil, Fakultas Teknik, Universitas Tridinanti Palembang \\ 1anifirda@univ-tridinanti.ac.id \\ 2indra.utp@gmail.com
}

\begin{abstract}
One of the added ingredients of concrete is fiber. The fiber in concrete serves to prevent cracks so as to make concrete more ductile and to increase the tensile strength of concrete. The use of concrete in an aggressive environment is very influential on the strength and value of the compressive and tensile strength of concrete. Concrete structures can be said to be in an aggressive environment when concrete is constantly in the environment of sea water, swamp water, soil, and industrial areas where it contains sulfate, the concrete will be susceptible to sulfate attack which can reduce the durability of concrete and can make concrete become corrosion. Therefore, in this study will examine how much influence the variations in water immersion PDAM Tirta Musi $(\mathrm{pH}=7)$ and swamp water $(\mathrm{pH}<7)$ and on the compressive strength and flexural strength with additional purun tikus fibers (eleocharis dulcis) of $0.75 \%$ for 28 days. The results showed that the immersion of concrete quality $f_{c}{ }^{\prime}=20 M p a$ at 28 days using $\operatorname{swamp}$ water $(p H=4.5)$, can reduce the compressive strength of normal concrete by $11.63 \%$, whereas in purun tikus concrete $0.75 \%$ by $4.12 \%$, compared to water immersion concrete of PDAM Tirta Musi $(p H=6.5)$. Soaking quality $f c$ 'concrete $=20 \mathrm{Mpa}$ age of 28 days using swamp water $(\mathrm{pH}=4.5)$, can reduce the flexural strength of normal concrete by $14.8 \%$, while in purun tikus concrete $0.75 \%$ by $5.8 \%$, compared to water immersion concrete of PDAM Tirta Musi $(\mathrm{pH}=6.5)$.
\end{abstract}

Keywords: water $p H$, compressive strength, flexural strength, purun tikus fiber

\begin{abstract}
ABSTRAK
Salah satu bahan tambah beton ialah serat. Serat dalam beton berfungsi untuk mencegah retakretak sehingga menjadikan beton lebih daktail dan untuk meningkatkan kekuatan tarik beton. Pemakaian beton pada lingkungan agresif sangat berpengaruh pada keawatan dan nilai kuat tekan dan tarik beton. Struktur beton dapat dikatakan berada pada lingkungan agresif manakala beton terus-menerus berada dalam lingkungan air laut, air rawa, tanah, dan kawasan industri dimana banya terkandung sulfat, beton akan menjadi rentan terhadap serangan sulfat yang dapat mengurangi durabilitas beton dan dapat membuat beton menjadi korosi. Oleh karena itu dalam penelitian ini akan meneliti mengenai seberapa besar pengaruh variasi perendaman air PDAM Tirta Musi $(\mathrm{pH}=7)$ dan air rawa $(\mathrm{pH}<7)$ dan terhadap kuat tekan dan kuat lentur dengan tambahan serat purun tikus (eleocharis dulcis) sebesar 0.75\% selama 28 hari. Hasil penelitian menunjukkan bahwa Perendaman beton mutu fc' $=20$ Mpa umur 28 hari menggunakan air rawa $(\mathrm{pH}=4.5)$, dapat menurunkan kuat tekan beton normal sebesar $11.63 \%$, sedangkan pada beton purun tikus $0.75 \%$ sebesar $4.12 \%$, dibanding beton perendaman air PDAM Tirta Musi ( $p H=6.5)$. Perendaman beton mutu $f_{c}{ }^{\prime}=20$ Mpa umur 28 hari menggunakan air rawa $(p H=4.5)$, dapat menurunkan kuat lentur beton normal sebesar $14.8 \%$, sedangkan pada beton purun tikus $0.75 \%$ sebesar 5.8\%, dibanding beton perendaman air PDAM Tirta Musi $(p H=6.5)$.
\end{abstract}

Keywords: pH air, kuat tekan, kuat lentur, serat purun tikus 


\section{JURNAL FORUM MEKANIKA}

Vol. 9, No. 1, Mei 2020, P-ISSN: 2356-1491, E-ISSN: 2655-8211

DOI: https://doi.org/10.33322/forummekanika.v9i1.883

\section{PENDAHULUAN}

Bahan pembentuk beton terdiri dari semen, agregat halus, agregat kasar, air dan bahan tambah jika diperlukan. Bahan tambah adalah bahan-bahan yang ditambahkan ke dalam campuran beton pada saat atau selama pencampuran berlangsung. Pemberian bahan tambah pada adukan beton bertujuan untuk memperlambat waktu pengikatan, mempercepat pengerasan, menambah encer adukan, menambah daktilitas (mengurangi sifat getas), mengurangi retak-retak pengerasan, mengurangi panas hidrasi, menambah kekedapan, menambah keawetan dan sebagainya [6].

Salah satu bahan tambah beton ialah serat (fiber). Beton yang diberi bahan tambah serat disebut beton serat (fiber concrete). Serat berfungsi mencegah retak-retak sehingga menjadikan beton lebih daktail dari beton biasa dan untuk meningkatkan kekuatan tarik beton.

Serat Purun Tikus (eleocharis dulcis) merupakan salah satu material natural fibre alternative. Purun tikus adalah tumbuhan liar yang banyak terdapat di lahan rawa pasang surut. Tumbuhan ini mempunyai rimpang pendek dengan stolon memanjang berujung bulat gepeng, berwarna kecoklatan sampai hitam. Batang tegak, tidak bercabang, berwarna keabuan hingga hijau mengkilap dengan panjang 50-200 $\mathrm{cm}$ dan tebal 2-8 $\mathrm{mm}$. Tanaman ini mempunyai serat yang cukup kuat karena memiliki tekstur serat seperti tali yang bisa melebihi kuat tarik pada rotan atau bambu [1].

Dalam pembuatan beton secara ilmiah, pemanfaatan serat purun tikus belum ada, sehingga beton dengan tambahan serat ini ini diharapkan mampu memberi nilai tambah kuat tekan maupun lentur beton. Dari segi ketersediaan, di propinsi Sumatera Selatan memiliki bahan baku serat purun tikus yang cukup melimpah, karena tanaman purun tikus banyak dijumpai di daerah pasang surut yang bertanah sulfat asam, sehingga penggunaannya akan memiliki specific cost yang rendah.

Selain serat sebagai bahan campuran beton, air juga merupakan salah satu faktor penting dalam pembuatan beton, karena air bereaksi dengan semen akan menjadi pasta pengikat agregat. Pada pembuatan beton, air yang digunakan haruslah air dengan $\mathrm{pH}$ netral dengan nilai 7. Pada daerah pedalaman sangat susah mendapatkan air yang bersih, para kontraktor biasanya membuat sumur atau menggunakan sungai yang ada pada daerah tersebut. Air yang didapat pada sumur dan sungai bisa jadi ber $\mathrm{pH}$ Asam ataupun Basa, sehingga air yang digunakan tidak memenuhi persyaratan. Hal ini dapat berpengaruh terhadap mutu atau kualitas beton.

Lingkungan asam yang mengandung unsur kimia asam akan merusak beton secara perlahanlahan mulai dari tepi dan sudut beton, dengan terjadinya pelepasan butiran-butiran partikel beton sehingga beton menjadi keropos [3]. Jika beton keropos, maka ikatan antara pasta beton dengan agregat akan semakin berkurang sehingga terjadi penurunan kuat tekan beton. Lahan gambut adalah salah satu lingkungan asam yang menjadi perhatian khusus di dunia konstruksi beton. Kandungan air gambut memiliki intensitas warna tinggi (coklat kemerahan), $\mathrm{pH}$ rendah, kandungan zat organik tinggi, kekeruhan dan kandungan partikel tersuspensi rendah dan tingkat kesadahan yang rendah. Air gambut dengan kandungan zat organik yang tinggi memiliki derajat keasaman $(\mathrm{pH})$ yang rendah dan mengakibatkan air tersebut bersifat asam [2]. Derajat keasaman air gambut dapat menimbulkan masalah korosi pada tulangan beton.

Pemakaian beton pada lingkungan agresif berpengaruh pada keawatan dan nilai kuat tekan dan lentur beton. Struktur beton dapat dikatakan berada pada lingkungan agresif bila beton terus berada dalam lingkungan air laut, air rawa, tanah, dan kawasan industri yang banyak terkandung sulfat, beton akan rentan terhadap serangan sulfat yang dapat mengurangi durabilitas beton [5].

Sementara lingkungan tanah yang terkontaminasi bahan kimia agresif dapat merusak bangunan bawah tanah seperti struktur pondasi, basement, tunel ataupun bangunan penahan tanah. 
Pemakaian struktur beton yang kontak langsung dengan senyawa asam sulfat akan mempengaruhi kualitas kuat tekan beton karena dapat membuat beton menjadi korosi. Oleh karena itu dalam penelitian ini akan meneliti mengenai bagaimana pengaruh variasi perendaman beton purun tikus terhadap kuat tekan dan lentur beton selama 28 hari.

\section{METODOLOGI / PERANCANGAN PENELITIAN}

Penelitian ini dilakukan di Laboratorium Beton di Fakultas Teknik Universitas Tridinanti Palembang, mulai April hingga September 2019.

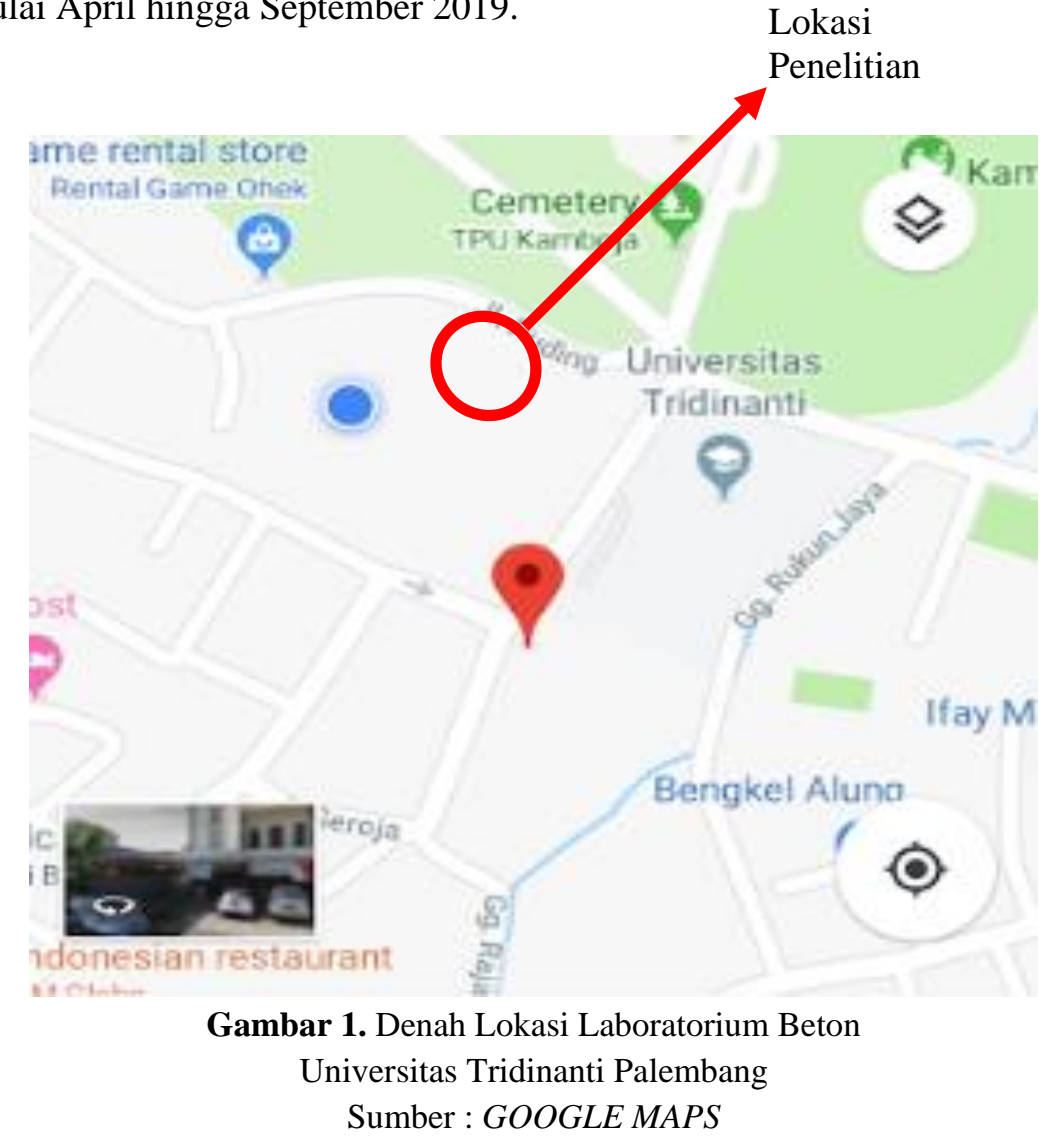

Data yang digunakan dalam penelitian ini terdiri dari data primer dan sekunder. Data primer dilakukan dengan metode eksperimen terhadap benda uji dari berbagai kondisi perlakuan. Diuji di Lab. Beton Universitas Tridinanti Palembang. Data sekunder didapat dari literatur penelitian sebelumnya, buku dan jurnal.

Alur penelitian ini dimulai dari pengujian bahan yang terdiri dari agregat kasar dan agregat halus, meliputi pengujian berat jenis, kadar air, berat isi, kadar lumpur, analisa saringan dan keausan agregat. Setelah pemeriksaan aggregat dilakukan dibuat rencana campuran (job mix design) dengan mutu beton $\mathrm{fc}^{\prime}=20 \mathrm{MPa}$, pembuatan campuran beton mengacu pada peraturan SK SNI 7656-2012 yaitu Tata cara pemilihan campuran untuk beton normal, beton berat dan beton massa [4]. Proses selanjutnya adalah pembuatan benda uji, benda uji dibuat dengan cetakan silinder diameter $150 \mathrm{~mm}$ dan tinggi $300 \mathrm{~mm}$. Untuk pengujian kuat tekan beton masing-masing persentase (\%) dan umur beton di buat 3 benda uji dengan perendaman menggunakan $\mathrm{pH}$ air yang berbeda. Untuk pengujian kuat lentur beton masing-masing persentase (\%) dengan umur beton 28 hari 


\section{JURNAL FORUM MEKANIKA}

Vol. 9, No. 1, Mei 2020, P-ISSN: 2356-1491, E-ISSN: 2655-8211

DOI: https://doi.org/10.33322/forummekanika.v9i1.883

dibuat sebanyak 3 benda uji dengan perendaman menggunakan $\mathrm{pH}$ air yang berbeda. Berikut tabel jumlah benda uji :

Tabel 1. Jumlah Sampel Kuat Tekan Beton Normal dan Komposisi Serat Tanaman Purun Tikus

\begin{tabular}{|c|c|c|c|c|}
\hline No & $\begin{array}{c}\text { Komposisi Tambahan } \\
\text { Serat Purun Tikus }\end{array}$ & Usia Beton & $\begin{array}{c}\text { Jumlah Sampel } \\
\text { (Perendaman Air } \\
\mathrm{pH} \text { Normal) }\end{array}$ & $\begin{array}{c}\text { Jumlah Sampel } \\
\text { (Perendaman Air } \\
\mathrm{pH} \text { Asam) }\end{array}$ \\
\hline 1 & BN $(0 \%)$ & $\begin{array}{c}\text { 3 hari, 7 hari, 14 hari, } \\
21 \text { hari } 28 \text { hari }\end{array}$ & 15 sampel & 15 sampel \\
\hline 2 & BSP $(0,75 \%)$ & $\begin{array}{c}\text { 3 hari, 7 hari, 14 hari, } \\
21 \text { hari } 28 \text { hari }\end{array}$ & 15 sampel & 15 sampel \\
\hline \multicolumn{2}{|c|}{ Total } & 30 sampel & 30 sampel \\
\hline
\end{tabular}

Tabel 2. Jumlah Sampel Kuat Tarik Belah Beton dan Komposisi Serat Tanaman Purun Tikus

\begin{tabular}{|c|c|c|c|c|}
\hline No & $\begin{array}{c}\text { Komposisi Tambahan } \\
\text { Serat Purun Tikus }\end{array}$ & Usia Beton & $\begin{array}{c}\text { Jumlah Sampel } \\
\text { (Perendaman Air } \mathrm{pH} \\
\text { Normal })\end{array}$ & $\begin{array}{c}\text { Jumlah Sampel } \\
\text { (Perendaman Air } \mathrm{pH} \\
\text { Asam })\end{array}$ \\
\hline 1 & BN $(0 \%)$ & 28 hari & 3 sampel & 3 sampel \\
\hline 2 & BSP $(0,75 \%)$ & 28 hari & 3 sampel & 3 sampel \\
\hline \multicolumn{2}{|c|}{ Total } & 6 sampel & 6 sampel \\
\hline
\end{tabular}

Material yang digunakan pada penelitian ini terdiri dari :

1) Semen yang digunakan dalam penelitian ini adalah Semen Portland Komposite (Portland Composite Cement) merk Semen Baturaja.

2) Agregat kasar yang digunakan adalah batu pecah (split) ukuran maksimum $25 \mathrm{~mm}$ dan minimum $19 \mathrm{~mm}$ yang berasal dari Lahat.

3) Agregat halus yang digunakan adalah pasir dari Tanjung Raja Ogan Komering Ilir (OKI)

4) Serat Tanaman Purun tikus didapat di daerah Indralaya Ogan Komering Ilir (OKI).

5) Air yang digunakan dari air PDAM Tirta Musi Palembang dan Air Rawa yang berasal dari Indralaya Ogan Komering Ilir (OKI).

Tahapan pembuatan sampel beton normal yaitu adalah sebagai berikut:

1. Adukan beton yang telah siap dimasukkan kedalam cetakan silinder sebanyak tiga lapis dengan masing-masing lapis ketebalannya $1 / 3$ dari volume cetakan silinder.

2. Disetiap lapis dilakukan pemadatan dengan cara ditusuk-tusuk dengan besi pemadat sebanyak 25 kali tusukan secara merata di setiap lapisannya sampai cetakan penuh.

3. Setelah langkah 1 dan 2 telah dilakukan, permukaan atas adukan beton diratakan dengan bagian atas cetakan.

Tahapan pembuatan sampel beton purun adalah sebagai berikut:

1. Adukan beton yang telah diaduk rata di taburkan serat purun ukuran $\pm 2 \mathrm{~cm}$ sedikit-sedikit sesuai presentase yang di rencanakan kemudian aduk lagi sampai rata.

2. Masukkan kedalam cetakan silinder sebanyak tiga lapis, masing-masing lapis ketebalannya $1 / 3$ dari volume cetakan silinder.

3. Disetiap lapis dilakukan pemadatan dengan cara ditusuk-tusuk dengan besi pemadat sebanyak 25 kali tusukan secara merata di setiap lapisannya sampai cetakan penuh.

4. Setelah langkah 1,2 dan 3 telah dilakukan, permukaan atas adukan beton diratakan dengan bagian atas cetakan. 
Sebelum melakukan proses pembuatan benda uji, terlebih dahulu dilakukan uji slump ( slump test). Benda uji yang telah dicetak dalam umur 24 jam dibuka cetakannya kemudian diselimuti dengan karung goni yang telah di siram dengan air dengan periode tertentu. Selanjutnya direndam dengan menggunakan air $\mathrm{pH}$ normal dan air $\mathrm{pH}$ Asam hingga satu hari sebelum benda diuji. Pengujian dilakukan terhadap kuat tekan dan kuat lentur beton. Adapun langkah pengujian kuat tekan dan lentur beton terhadap beton normal dan beton purun yang melalui proses perendaman dengan air $\mathrm{pH}$ normal dan air $\mathrm{pH}$ Asam adalah sebagai berikut:

a. Uji Kuat Tekan Beton

1. Keluarkan benda uji dari tempat perendaman sehari sebelum benda di uji.

2. Benda uji ditimbang berat dan volumenya.

3. Letakkan benda uji secara sentris pada mesin kuat tekan beton.

4. Catatlah beban maksimum yang terjadi selama pengujian berlangsung.

5. Lakukan pada semua benda uji yang akan di uji kuat tekan beton.

b. Uji Kuat Tarik Belah Beton

1. Keluarkan benda uji dari tempat perendaman sehari sebelum benda di uji.

2. Benda uji ditimbang berat dan volumenya.

3. Letakkan benda uji pada mesin uji kuat tarik belah beton yang dilapisi plat diatas dan dibawah benda uji.

4. Selama pengujian berlangsung mesin uji akan menekan benda uji hingga terbelah.

5. Mencatat hasil kuat tarik belah beton hingga semua benda uji yang akan di uji kuat tarik belah beton.

\section{HASIL DAN PEMBAHASAN}

\subsection{Deskripsi Pembuatan Benda Uji}

Sampel benda uji dengan dua variasi yaitu beton normal dan beton campuran serat purun $0,75 \%$. Cetakan yang digunakan berbentuk silinder ukuran $150 \mathrm{~mm}$ x $300 \mathrm{~mm}$, dan balok ukuran $150 \mathrm{~mm}$ x $150 \mathrm{~mm} \times 600 \mathrm{~mm}$. Pertama kali yang dilakukan adalah menimbang seluruh material yang akan digunakan sesuai dengan perencanaan campuran yang telah dibuat. Kemudian material dicampur menggunakan mesin pengaduk hingga tercampur rata. Selanjutnya dilakukan pengujian slump, dan dicetak kedalam cetakan silinder dan balok yang sudah dilumasi oli. Cetakan dibuka setelah 24 jam, kemudian perawatan benda uji dengan cara merendam benda uji kedalam air hingga satu hari sebelum tanggal pengujian, sehingga pada saat pengujian benda uji dalam keadaan kering. Setelah mencapai waktu yang ditentukan benda uji ditimbang dan dilakukan pengujian kuat tekan dan kuat lentur.

\subsection{Hasil Uji Slump}

Uji slump untuk perencanaan struktur sebesar $10 \pm 2$ yang dilakukan untuk mengukur kekentalan adukan beton. Perbandingan hasil uji slump antara beton normal dan beton purun tikus dengan variasi $0,75 \%$ dapat dilihat pada tabel 3 dibawah ini.

Tabel 3. Hasil Pengujian Slump Beton

\begin{tabular}{|c|c|}
\hline Variasi & Nilai Slump Beton \\
\hline Beton Normal & $10 \mathrm{~cm}$ \\
\hline Beton Purun Tikus $0.75 \%$ & $8 \mathrm{~cm}$ \\
\hline
\end{tabular}

Sumber : Hasil Penelitian di Laboratorium 


\section{JURNAL FORUM MEKANIKA}

Vol. 9, No. 1, Mei 2020, P-ISSN: 2356-1491, E-ISSN: 2655-8211

DOI: https://doi.org/10.33322/forummekanika.v9i1.883

Dari tabel 3 diatas, dapat dilihat hasil slump beton normal sebesar $10 \mathrm{~cm}$, dan beton purun sebesar $8 \mathrm{~cm}$.

\subsection{Data Hasil Pengujian Kuat Tekan dan Kuat Lentur Beton}

Data Pengujian kuat tekan dan kuat lentur beton normal dan beton purun menggunakan air pH Normal (Air PDAM Tirta Musi pH=6.5) dan air pH Asam (Air Rawa pH=4,5) adalah sebagai berikut:

a. Kuat Tekan Beton Normal

Kuat tekan rata-rata beton normal perendaman air PDAM Tirta Musi dan air rawa adalah sebagai berikut :

Tabel 4. Rekapitulasi Hasil Pengujian Kuat Tekan Beton Normal

\begin{tabular}{|c|c|c|c|c|c|c|}
\hline \multirow{2}{*}{ Kondisi Beton } & \multicolumn{7}{|c|}{ Umur Beton ( Hari ) } \\
\cline { 2 - 7 } & 3 & 7 & 14 & 21 & 28 & $\sigma \mathrm{bk}$ \\
\hline $\begin{array}{c}\text { Beton normal } \\
\text { (Air PDAM) }\end{array}$ & 12.4 & 15.00 & 16.73 & 19.52 & 22.60 & $\mathrm{~kg} / \mathrm{cm}$ \\
\hline $\begin{array}{c}\text { Beton Normal } \\
\text { (Air Rawa) }\end{array}$ & 11.6 & 13.18 & 14.48 & 17.77 & 19.97 & $\mathrm{~kg} / \mathrm{cm}$ \\
\hline
\end{tabular}

Sumber : Hasil Penelitian di Laboratorium

Grafik perbandingan antara kuat tekan beton normal menggunakan perendaman air PDAM Tirta Musi dan air rawa seperti dibawah ini :

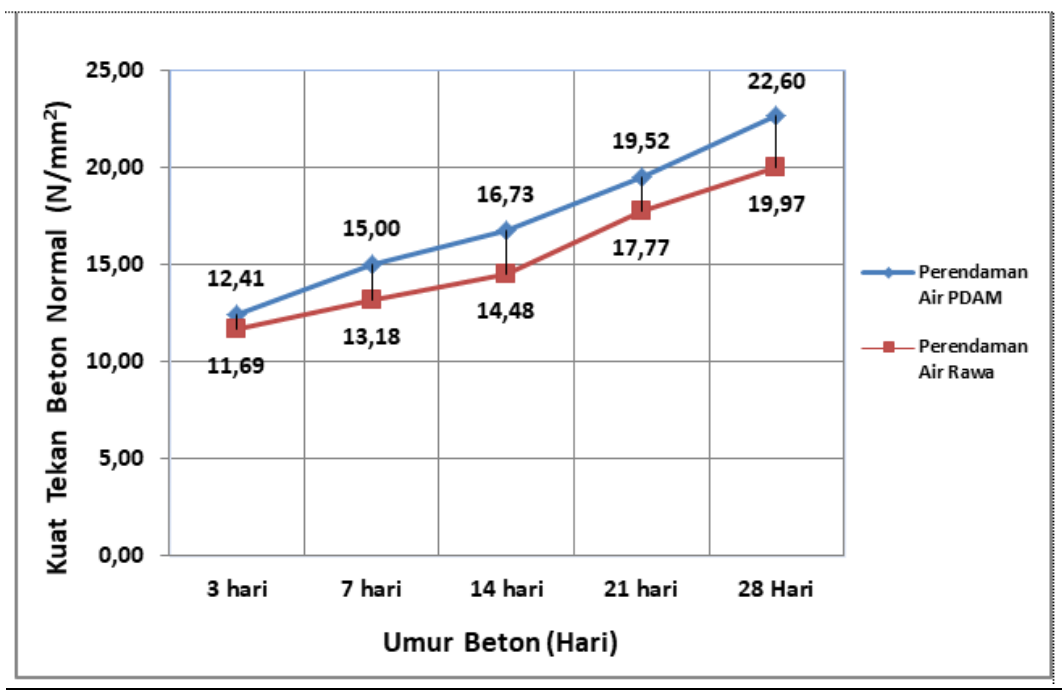

Gambar 2. Perbandingan Kuat Tekan Beton Normal Perendaman Air PDAM dan Air Rawa

b. Kuat Tekan Beton Purun Tikus $0.75 \%$

Kuat tekan rata-rata beton purun perendaman air PDAM Tirta Musi dan air rawa adalah sebagai berikut : 
Tabel 5. Rekapitulasi Hasil Pengujian Kuat Tekan Beton Purun Tikus 0.75\%

\begin{tabular}{|c|c|c|c|c|c|c|}
\hline \multirow{2}{*}{ Kondisi Beton } & \multicolumn{6}{|c|}{ Umur Beton ( Hari ) } \\
\cline { 2 - 7 } & 3 & 7 & 14 & 21 & 28 & $\sigma \mathrm{bk}$ \\
\hline $\begin{array}{c}\text { Beton Purun } \\
\text { (Air PDAM) }\end{array}$ & 10.3 & 13.0 & 14.62 & 17.31 & 19.62 & $\mathrm{~kg} / \mathrm{cm} 2$ \\
\hline $\begin{array}{c}\text { Beton Purun } \\
\text { (Air Rawa) }\end{array}$ & 10.0 & 12.5 & 13.82 & 16.64 & 18.81 & $\mathrm{~kg} / \mathrm{cm} 2$ \\
\hline
\end{tabular}

Sumber : Hasil Penelitian di Laboratorium

Grafik perbandingan antara kuat tekan beton purun menggunakan perendaman air PDAM Tirta Musi dan air rawa adalah:

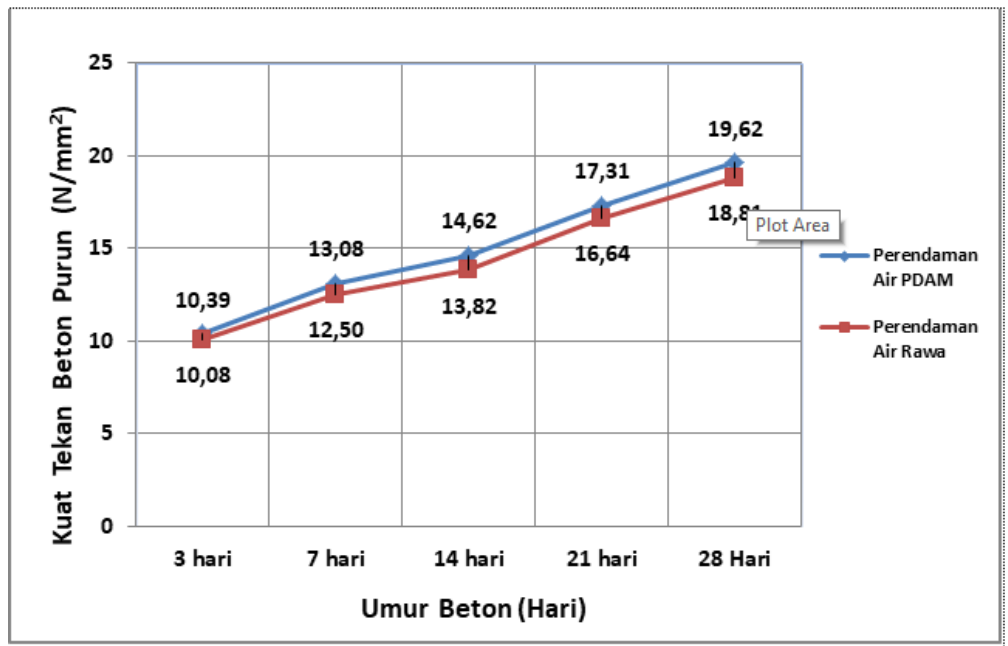

Gambar 3. Perbandingan Kuat Tekan Beton Purun Perendaman Air PDAM dan Air Rawa

c. Kuat Lentur Beton Normal

Kuat lentur beton normal perendaman air PDAM Tirta Musi dan air Rawa adalah :

Tabel 6. Rekapitulasi Hasil Pengujian Kuat Lentur Beton Normal

\begin{tabular}{|c|c|c|}
\hline \multirow{2}{*}{ Kondisi Beton } & \multicolumn{2}{|c|}{ Umur 28 Hari } \\
\cline { 2 - 3 } & Kuat Lentur & $\sigma \mathrm{bk}$ \\
\hline $\begin{array}{c}\text { Beton Normal } \\
\text { (Air PDAM) }\end{array}$ & 22.90 & $\mathrm{~kg} / \mathrm{cm} 2$ \\
\hline $\begin{array}{c}\text { Beton Normal } \\
\text { (Air Rawa) }\end{array}$ & 19.51 & $\mathrm{~kg} / \mathrm{cm} 2$ \\
\hline
\end{tabular}

Sumber : Hasil Penelitian di Laboratorium

Grafik perbandingan antara kuat lentur beton normal menggunakan perendaman air PDAM Tirta Musi dan air rawa seperti dibawah ini: 


\section{JURNAL FORUM MEKANIKA}

Vol. 9, No. 1, Mei 2020, P-ISSN: 2356-1491, E-ISSN: 2655-8211

DOI: https://doi.org/10.33322/forummekanika.v9i1.883

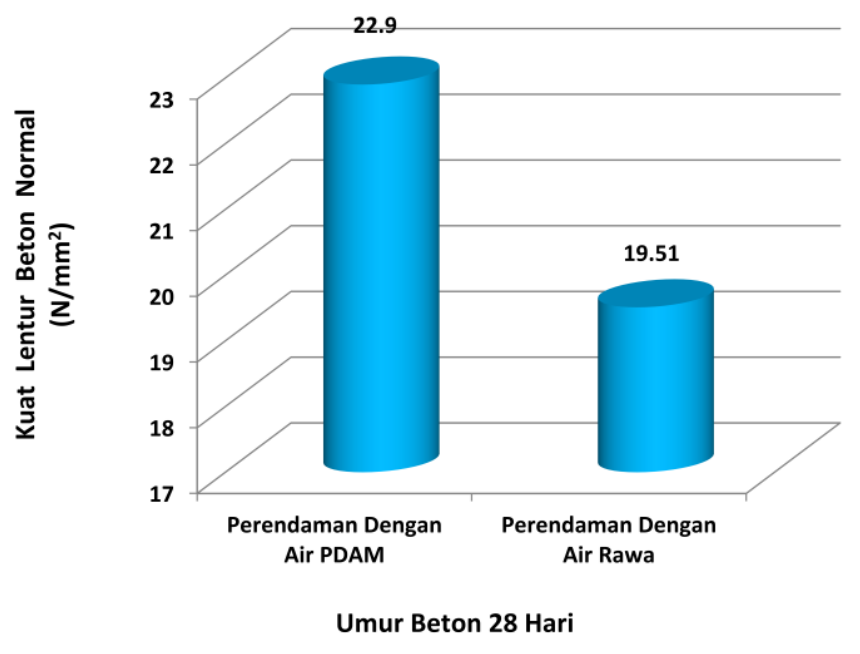

Gambar 4. Perbandingan Kuat Lentur Beton Normal Perendaman Air PDAM dan Air Rawa

d. Kuat Lentur Beton Purun Tikus $0.75 \%$

Kuat lentur beton purun perendaman air PDAM Tirta Musi $(\mathrm{pH}=6.5)$ dan Air Rawa $(\mathrm{pH}=4.5)$ adalah :

Tabel 7. Rekapitulasi Hasil Pengujian Kuat Lentur Beton Purun Tikus 0.75\%

\begin{tabular}{|c|c|c|}
\hline \multirow{2}{*}{ Kondisi Beton } & \multicolumn{2}{|c|}{ Umur 28 Hari } \\
\cline { 2 - 3 } & Kuat Lentur & $\sigma \mathrm{bk}$ \\
\hline $\begin{array}{c}\text { Beton Purun Tikus 0.75\% } \\
\text { (Air PDAM) }\end{array}$ & 20.13 & $\mathrm{~kg} / \mathrm{cm}^{2}$ \\
\hline $\begin{array}{c}\text { Beton Purun Tikus 0.75\% } \\
\text { Purun (Air Rawa) }\end{array}$ & 18.96 & $\mathrm{~kg} / \mathrm{cm}^{2}$ \\
\hline
\end{tabular}

Sumber : Hasil Penelitian di Laboratorium

Grafik perbandingan antara kuat lentur beton purun menggunakan perendaman air PDAM Tirta Musi dan air rawa seperti dibawah ini:

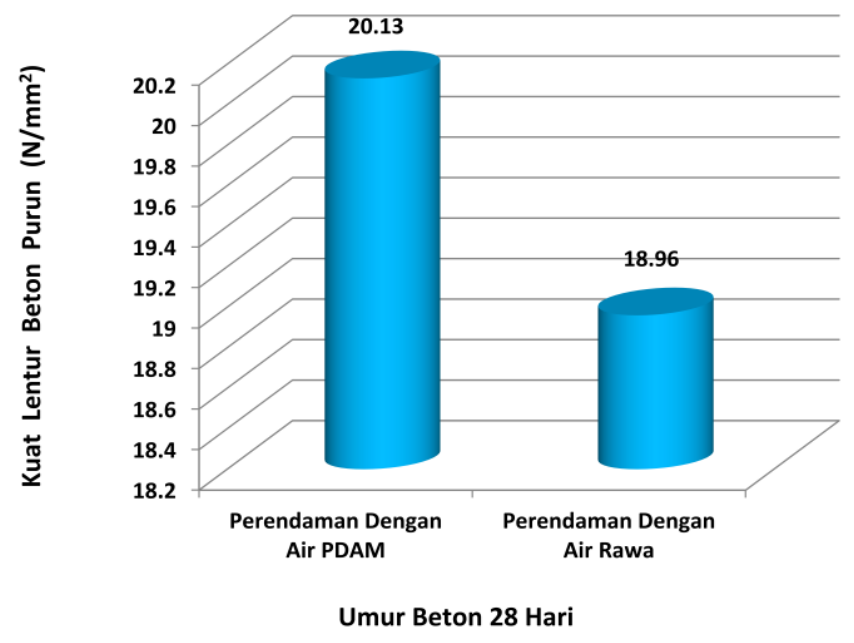

Gambar 5. Perbandingan Kuat Lentur Beton Purun Perendaman Air PDAM dan Air Rawa 


\subsection{Analisa Hasil Pengujian Kuat Tekan}

Hasil pengujian kuat tekan dan kuat lentur beton normal dan beton purun tikus $0.75 \%$ menggunakan Air PDAM Tirta Musi ( $\mathrm{pH}=6.5)$ dan Air Rawa ( $\mathrm{pH}=4.5)$ adalah :

a. Kuat Tekan Beton Normal

Berdasarkan Tabel 4 dan Gambar 2, didapat beton normal perendaman air PDAM Tirta Musi umur 28 hari memiliki kuat tekan sebesar $22.60 \mathrm{Mpa}$, perendaman air rawa umur 28 hari memiliki kuat tekan sebesar 19.97 Mpa. Beton normal perendaman air PDAM Tirta Musi umur 28 hari memiliki kuat tekan yang lebih tinggi dibanding perendaman air rawa. Ini menunjukkan bahwa perendaman air rawa dapat menurunkan kuat tekan beton sebesar 11,63\%.

b. Kuat Tekan Beton Purun Tikus 0.75\%

Berdasarkan Tabel 5 dan Gambar 3, didapat beton purun tikus $0.75 \%$ perendaman air PDAM Tirta Musi umur 28 hari memiliki kuat tekan sebesar $19.62 \mathrm{Mpa}$, perendaman air rawa umur 28 hari memiliki kuat tekan sebesar $18.81 \mathrm{Mpa}$. Beton purun tikus $0.75 \%$ perendaman air PDAM Tirta Musi umur 28 hari memiliki kuat tekan yang lebih tinggi dibanding perendaman air rawa. Ini menunjukkan bahwa perendaman air rawa dapat menurunkan kuat tekan beton sebesar $4.12 \%$.

c. Kuat Lentur Beton Normal

Berdasarkan Tabel 6 dan Gambar 4, didapat beton normal perendaman air PDAM Tirta Musi umur 28 hari memiliki kuat lentur sebesar $22.90 \mathrm{Mpa}$, perendaman air rawa umur 28 hari memiliki kuat lentur sebesar 19.51 Mpa. Beton normal perendaman air PDAM Tirta Musi umur 28 hari memiliki kuat lentur yang lebih tinggi dibanding perendaman air rawa. Ini menunjukkan bahwa perendaman air rawa dapat menurunkan kuat lentur beton sebesar $14.80 \%$.

d. Kuat Lentur Beton Purun Tikus 0.75\%

Berdasarkan Tabel 7 dan Gambar 5, didapat beton purun tikus $0.75 \%$, perendaman air PDAM Tirta Musi umur 28 hari memiliki kuat lentur sebesar $20.13 \mathrm{Mpa}$, perendaman air rawa umur 28 hari memiliki kuat lentur sebesar $19.51 \mathrm{Mpa}$. Beton purun tikus $0.75 \%$ perendaman air PDAM Tirta Musi umur 28 hari memiliki kuat lentur yang lebih tinggi dibanding perendaman air rawa. Ini menunjukkan bahwa perendaman air rawa dapat menurunkan kuat lentur beton sebesar $5.81 \%$.

\section{KESIMPULAN DAN SARAN}

Kesimpulan yang dapat diambil dari penelitian ini yaitu perendaman beton mutu fc' = $20 \mathrm{Mpa}$ umur 28 hari menggunakan air rawa $(\mathrm{pH}=4.5)$ dapat menurunkan kuat tekan beton normal sebesar $11.63 \%$, sedangkan pada beton purun tikus $0.75 \%$ sebesar $4.12 \%$, dibanding beton perendaman air PDAM Tirta Musi $(\mathrm{pH}=6.5)$. Perendaman beton mutu $\mathrm{fc}^{\prime}=20 \mathrm{Mpa}$ umur 28 hari menggunakan air rawa $(\mathrm{pH}=4.5)$, dapat menurunkan kuat lentur beton normal sebesar $14.8 \%$, sedangkan pada beton purun tikus $0.75 \%$ sebesar $5.8 \%$, dibanding beton perendaman air PDAM Tirta Musi ( $\mathrm{pH}=6.5)$.

Sebelum proses pencampuran serat purun tikus sebaiknya serat tanaman purun dapat di potong dengan ukuran yang lebih kecil yaitu $1 \mathrm{~cm}-1,5 \mathrm{~cm}$ dan dicampurkan kedalam adukan beton secara bertahap, agar serat dapat tercampur dengan baik pada saat proses pengadukan dan pembuatan beton. Pada proses pembuatan beton dapat juga menambahkan bahan aditif seperti super plasticizer agar dapat meningkatkan mutu beton dan memudahkan dalam proses pengerjaan sampel beton (meningkatkan workability). 


\section{JURNAL FORUM MEKANIKA}

Vol. 9, No. 1, Mei 2020, P-ISSN: 2356-1491, E-ISSN: 2655-8211

DOI: https://doi.org/10.33322/forummekanika.v9i1.883

\section{UCAPAN TERIMA KASIH}

Ucapan terima kasih kepada Lembaga Penelitian dan Pengabdian Masyarakat (LPPM) Universitas Tridinanti Palembang untuk Dana Hibah Penelitian Yayasan Nasional Tridinanti Palembang Tahun Anggaran 2019, dan semua pihak yang telah membantu penelitian ini.

\section{DAFTAR PUSTAKA}

[1] S. Asikin, dan M. Thamrin, "Manfaat Purun Tikus (Eleocharis dulcis) Pada Ekosistem Sawah Rawa": Jurnal Penelitian dan Pengembangan Pertanian, Badan Litbang Pertanian, Kementrian Pertanian Republik Indonesia, 2012

[2] Kusnaedi, "Mengolah Air Gambut dan Kotor untuk Air Minum", Penebar Swadaya, Jakarta, Hal. 17-20, 2006.

[3] Purba, Parhimpuan, "Pengaruh Kandungan Sulfat terhadap Kuat Tekan Beton". UNDIP: Jurnal Teknik Sipil PSD III, UNDIP, 2006.

[4] SK SNI 7656-2012. "Tata Cara Pemilihan Campuran Untuk Beton Normal, Beton Brat dan Beton Massa”. Badan Standar Nasional, 2012.

[5] Stefanus dkk, dalam Belie 2007, "Resistensi Beton Memadat Mandiri yang Mengandung Fly Ash Tinggi Terhadap Serangan Asam Sulfat”, Konferensi Nasional Teknik Sipil (KoNTeks 7), Universitas Sebelas Maret, Surakarta, 2013.

[6] Tjokrodimuljo, "Teknologi Beton”, Nafiri, Yogyakarta, 2007. 